CUADERNOS DE ESTUDIOS GALLEGOS, LXII Núm. 128 (enero-diciembre 2015), págs. 305-333

ISSN: $0210-847 \mathrm{X}$

DOI: 10.3989/ceg.2015.128.10

\title{
VIOLENCIA RURAL INTERCOMUNITARIA NO SUESTE DE GALICIA. UN CASO CONCRETO: MOIALDE CONTRA SAN PEDRO DE POUSADA
}

\author{
Emilio Alonso Gayoso
}

Servizo Público de Emprego Estatal 


\title{
VIOLENCIA RURAL INTERCOMUNITARIA NO SUESTE DE GALICIA. UN CASO CONCRETO: MOIALDE CONTRA SAN PEDRO DE POUSADA
}

ResUMO

O obxectivo deste traballo é facer unha aproximación ao estudo da violencia rural a través da análise dos conflitos entre dúas aldeas do sueste de Galicia (Santa María de Moialde e San Pedro de Pousada), tanto por motivos económicos como sociais, mediante unha investigación cualitativa e a entrevista de varias testemuñas, coa intención de determinar as causas máis probables dos conflitos entre comunidades, tanto de natureza social como económica. A partir dos datos obtidos chégase á conclusión de que a maioría dos conflitos rurais no ámbito estudado orixínanse na competencia polas mulleres solteiras e polo acceso aos bens comunais, necesarios para a supervivencia cotiá.

Palabras clave: Galicia, violencia rural

\section{VIOLENCIA RURAL INTERCOMUNITARIA EN EL SUDESTE DE GALICIA. UN CASO CONCRETO: MOIALDE CONTRA SAN PEDRO DE POUSADA}

\section{RESUMEN}

El objetivo de este trabajo es realizar una aproximación al estudio de la violencia rural a través del análisis de los conflictos entre dos aldeas del sudeste de Galicia (Santa María de Moialde y San Pedro de Pousada), tanto por motivos económicos como sociales, mediante una investigación cualitativa y la entrevista de varios testigos, con la intención de determinar las causas más probables de los conflictos entre comunidades, tanto de naturaleza social como económica. A partir de los datos obtenidos se llega a la conclusión de que la mayoría de los conflictos rurales en el ámbito estudiado se originan en la competencia por las mujeres solteras y por el acceso a los bienes comunales, necesarios para la supervivencia cotidiana.

PALABRAS CLAVE: Galicia, violencia rural

\section{INTERCOMMUNAL VIOLENCE IN RURAL SOUTHEASTERN GALICIA. A PARTICULAR CASE: MOIALDE AGAINST SAN PEDRO DE POUSADA}

\begin{abstract}
The objective of this work is make an approximation to the research about the rural violence across the analysis of the conflict between two villages in the southeast of Galicia (Santa Maria de Moialde and San Pedro de Pousada), by economic and social causes, means of a cualitative research and the interview of several witness, with the design to determinate the most probable causes of the conflict between the communities, in economic and social nature. With the obtained dates, we reach to the conclusion that the most part of the rural conflict in the studied ambit begin in the competition to access to the single women and to the comunal goods, needful to the daily survival.

KEY wORDS: Galicia, rural violence
\end{abstract}


Recibido/Received: 31/01/2015

Aceptado/Accepted: 10/08/2015

$\mathrm{T}$

radicionalmente a historiografía prestou, de xeito maioritario, atención aos grandes acontecementos. Así, revoltas, revolucións ou batallas foron o seu tema principal, deixando no esquecemento outros fenómenos moito máis habituais pero menos rechamantes. Recentemente, esta carencia vén sendo atallada grazas, por exemplo, aos investigadores doutros ámbitos históricos (sociedade, economía, cultura), e máis concretamente, da vida cotiá. Esta tendencia historiográfica pódese definir como a corrente de investigación histórica que se centra no estudo dos modos de vida de individuos que pasaron inadvertidos para a historia tradicional (a dos grandes feitos baseada fundamentalmente en fontes documentais oficiais).

Dentro deses modos de vida, a violencia, presente na sociedade máis aló da violencia organizada ou exercida dende o ámbito militar ou policial, non recibiu un tratamento en profundidade ata fai escasas décadas.

Así, en Galicia, no tocante aos tipos de violencia, ao centrarse os estudos só nos acontecementos máis destacados, como os motíns ou as rebelións, deixábanse sen estudar outros aspectos como os da violencia cotiá.

Dentro desta estarían as formas de resistencia do campesiñado, definidas por Scott como as armas do débil ${ }^{1}$ (formas de resistencia de escaso risco levadas a cabo polo campesiñado en defensa dos seus intereses, como por exemplo, pequenos furtos, sabotaxes -verbigracia, incendios ou destrución de cultivos ou facenda-, caza furtiva ou evasión de impostos -declarando colleitas por debaixo da realidade-. Estas formas de resistencia caracterizábanse pola necesidade de pouca organización, a seguridade dos actuantes dentro do anonimato e pola súa verticalidade (a acción violenta ou a resistencia procedía de estratos socialmente inferiores contra os superiores). Tamén se producían outras de índole máis horizontal, que enfrontaba a distintos membros dun mesmo estrato social (estas non se incluirían dentro desta clasificación de Scott).

\footnotetext{
1 Jim C. ScotT, “Formas cotidianas de rebelión campesina”, Historia Social, 28 (1997), páxs. 13-39. Publicado orixinalmente en The Journal of Peasant Studies, vol 13, núm. 2 (1986).
} 
No caso da sociedade rural galega, existían moitos tipos de violencia. Destacaron, dende o século XVIII en adiante, os conflitos polo aproveitamento das terras comunais (primeiro contra os foreiros e logo entre os propios campesiños -dentro do mesmo núcleo de poboación ou con outros-), que serán uns dos tratados neste traballo. Pero os anteriores non eran os únicos. Tamén tiñan lugar disputas por cuestións de honra, resistencias antifiscais, loitas contra o sistema de quintas militares ou conflitos entre veciños por lindes de terras ou uso de regadíos. Neste sentido destaca o estudo realizado por Henrique Hervés Sayar².

A presente investigación centrarase nos conflitos rurais entre distintas comunidades (no sueste de Galicia nas décadas dos 40, 50 e 60 do século XX). Partindo dun breve estudo do estado da cuestión e valéndose dunha investigación cualitativa (baseada en entrevistas persoais e cuestionarios sobre un caso concreto de violencia intercomunitaria entre dúas aldeas), inténtanse achar as causas máis probables das orixes deste tipo de violencia e os motivos que fixeron que estes enfrontamentos sexan agora unha rareza.

Este traballo estrutúrase en catro grandes apartados. En primeiro lugar, unha introdución ao estado da cuestión nesta temática, con exemplos doutros países e da propia España. A continuación, explícase a metodoloxía seguida, os seus obxectivos, hipóteses e o deseño da investigación. Segue a análise dos resultados obtidos e finalmente, as conclusións do estudo e a bibliografía empregada.

\section{EstAdo DA CUESTIÓN}

Tradicionalmente, como xa se indicou anteriormente, este tipo de violencia non era obxecto de estudo, pasaba en gran parte desapercibida. Cando se realizaban análises ou investigacións, facíanse dende unha perspectiva dicotómica de campo-cidade, onde o campo (campesiñado) representaba o atraso, social e técnico, e a cidade (burguesía) o adianto. Polo tanto, era interpretada como unha manifestación de barbarie, de carencia de civilización e de primitivismo. Esta foi a tónica xeral durante o século XIX e parte do XX.

Recentemente comezaron a proliferar os estudos sobre violencia rural. Porén, no que á violencia intercomunitaria galega se refire, as achegas aínda son pouco numerosas destacando o traballo realizado polos historiadores Cabo Villaverde e Vázquez Varela ${ }^{3}$ (de próxima publicación na revista Hispania), que

\footnotetext{
2 Henrique Hervés SAYAR e outros, "Resistencia y organización. La conflictividad rural en Galicia desde la crisis del Antiguo Régimen al franquismo", Noticiario de Historia Agraria, 13 (1997), páxs. 165-191.

3 Miguel Cabo Villaverde e José Manuel Vázquez Varela. "Las otras guerras de nuestros antepasados: la violencia intercomunitaria en la Galicia rural contemporánea”, Inédito, 2014 (de próxima
} 
nestes momentos é a única investigación que se centra exclusivamente nesta temática.

Noutros países tamén se ten estudado o tema da violencia rural, a modo de exemplo pódese citar a investigación realizada por Irene Maria Vaquinhas en $1996^{4}$, que para o marco xeográfico do centro de Portugal entre os anos 1858 e 1919 , toma como fontes os procesos xudiciais. As causas desta violencia atópaas nos conflitos sobre a propiedade (uso de augas comúns, lindes de terras e uso dos comunais, que xa foran extinguidos nese país) e na honra (neste aspecto as mulleres eran representadas polas sentenzas como as causantes dos conflitos). Outra característica desta investigación é a redución da violencia debido á emigración e á diminución da demanda dos recursos que traía con ela. A perspectiva que presenta é a dunha violencia campesiña cunha fundamentación na conservación, reactiva ante a perda ou modificación dunha situación previa, xa sexa no eido da propiedade, xa sexa no campo da honra.

Outro estudo interesante nesta temática é o realizado por Caroline Conley en $1999^{5}$. Igual que no caso anterior a investigación toma como fontes rexistros oficiais, neste caso os rexistros de asasinatos en Irlanda entre 1866 e 1899. Aquí atopámonos ante un tipo de violencia grupal que pode derivar, a causa da solidariedade entre os contendentes, cara a pelexas tumultuosas nas que participan poboacións enteiras. Estes enfrontamentos eran considerados como unha especie de deporte (tiñan un aspecto recreativo), pois había unha serie de rituais como a provocación ou a falta de intencionalidade de facer dano (non estaba ben visto que se empregasen armas como navallas ou pistolas), que aumentaban a súa aceptación chegando a influír nos tribunais de xustiza que acostumaban a ser benévolos nas sentenzas.

Con respecto a outras partes de España, obsérvase que o tipo de fontes empregadas son semellantes (fontes xudiciais). Así, por exemplo, no artigo de Jesús A. Redondo-Cardeñoso de $2010^{6}$ (para o período comprendido entre 1917 e 1923 na provincia de Palencia) os tipos de violencia son maioritariamente non colectivos; violencia física contra as persoas e as cousas e violencia verbal (individuo contra individuo). Como único aspecto comunitario pódense citar as loitas polo uso das terras comunais entre os pastores, pero sen chegar a enfrontamentos de comuni-

publicación en Hispania). Aproveito a mención desta obra para agradecerlle a un dos autores, o profesor Cabo Villaverde, a posibilidade que me brindou de poder acceder á mesma.

${ }_{4}$ Irene Maria Vaquinhas, Violência, justiça e sociedade rural. Os campos de Comimbra, Montamor-o-Velho e Penacova de 1858 a 1918, Porto, Afrontamento, 1996.

5 Carolyn Conley, "The Agreeable Recreation of Fighting", Journal of Social History, 33 (1) (1999), páxs. 57-72.

6 Jesús Ángel Redondo-Cardeñoso, "Violencia y sociedad rural. La Tierra de Campos palentina (1917-1923)”, Historia Agraria, 51 (2010), páxs. 81-108. 
dades unhas coas outras. Ao igual que concluía Irene M. Vaquinhas, a violencia rural ten unha función conservadora de mantemento do statu quo.

Pasando ao ámbito galego, atópanse estudos xerais sobre a violencia rural, pero sen tratar en profundidade a violencia intercomunitaria. Así, Henrique Hervés Sayar e outros ${ }^{7}$ realizan unha investigación sobre distintos tipos de violencia rural en Galicia dende mediados do século XVIII ata o Franquismo. Porén, a violencia entre comunidades non é abordada. Se se tratan conflitos derivados do uso dos montes comúns, pero dende unha perspectiva intracomunitaria, contra a apropiación de parte dos mesmos por algún veciño ou polo seu paso a mans públicas. Por outra banda, outro aspecto destacable desta investigación (en especial para a presente obra, pois aquí se inscribe o seu marco temporal) é a representación da ditadura de Franco como causante da diminución dos conflitos, por mor da súa labor coercitiva.

Dende un punto de vista antropolóxico, o tipo de violencia que se estuda nesta investigación (intercomunitaria) foi tratado dentro do marco xeral das costumes galegas. Neste sentido, merecen mención varias obras: C. Lison Tolosana ${ }^{8}$, Pegerto Saavedra ${ }^{9}$ e Xosé Rodríguez Cruz e António Lorenço Fontes ${ }^{10}$.

Nestes estudos, sen afondar no tema, enuncian as causas dos conflitos entre as comunidades, por un lado a competencia polas mozas (os mozos vían con malos ollos que as mulleres da súa aldea moceasen con xente de fóra da comunidade) e, por outro, a competencia polo uso de zonas de comunal. Destaca o feito de marcar como momentos de maiores enfrontamentos as distintas festas padroais. Os dous primeiros estudos (máis antigos) teñen un carácter máis xeral, mentres que o terceiro, máis recente, refírese a zona fronteiriza con Portugal do leste de Ourense (e a súa zona equivalente no país veciño). Zona na que, por outra banda, tamén se centra este estudo.

Outro exemplo do incipiente estudo desta temática é a obra realizada por Xavier Castro $^{11}$, que na mesma liña que os tres estudos anteriores trata como unha parte máis da súa investigación as causas deste tipo de violencia; coincidindo cos tres anteriores: mozas e uso dos comunais.

Finalmente, como estudo máis destacado atopamos o, inédito e xa citado, de Miguel Cabo Villaverde e José M. Vázquez Varela, o cal é tomado como referencia

\footnotetext{
7 H. Hervés SAYAR e outros, "Resistencia y organización...”, páxs. 165-191.

8 Carmelo Lison Tolosana, Antropología cultural de Galicia, Madrid, Akal, 1979.

9 Pegerto SaAvedra Fernández, La vida cotidiana en la Galicia del Antiguo Régimen, Barcelona, Crítica, 1994.

${ }^{10}$ Xosé Rodríguez Cruz e António Lorenço Fontes, Mitos, crenzas e costumes da Raia Seca, Vigo, Ir Indo, 2004.

${ }^{11}$ Xavier Castro Pérez, Servir era o pan do demo. Historia da vida cotiá en Galicia. Séculos XIX e XX, Vigo, Nigraterra, 2007.
} 
principal para a realización do presente traballo. O único que, de momento, se centra en exclusiva nesta temática. Esta investigación presenta unha explicación xenérica para este fenómeno para o conxunto da Galicia de finais do século XIX e principios do XX. As causas da violencia son coincidentes coas expostas nas anteriores investigacións (mozas e uso dos bens produtivos comunais). Actuando nestas contendas, como elementos catalizadores, inimizades previas entre os participantes. Como data de finalización deste tipo de actuacións marca a década dos 50 , co comezo da emigración xeneralizada.

\section{Metodoloxía}

Neste traballo, para dar resposta aos obxectivos e aos supostos e hipóteses que seguen, optouse por unha metodoloxía baseada en fontes fundamentalmente cualitativas (entrevistas persoais). A razón disto baséase na necesidade de achegar aspectos subxectivos (pareceres e sentimentos), que se obteñen con maior facilidade por medio da historia oral, a procesos de mudanza de actitudes e moral que tiveron lugar na Galicia de mediados do século XX. Pois, por medio do estudo, por exemplo, unicamente de documentación oficial, non se chegará ás motivacións e aos sentimentos dos participantes nun proceso histórico determinado.

\subsection{Obxectivos}

A misión desta investigación é achegar luz a un aspecto do mundo rural galego que foi apenas estudado. Para iso, céntrase nun período aproximado de tres décadas (1940-1969). Así, preténdese:

1. Identificar as causas máis probables da violencia intercomunitaria. Saber se, neste caso concreto, son comúns ás propostas noutras investigacións e coñecer como as ven as xentes que viviron eses feitos.

2. Saber quen participaba nos actos violentos. Quen o facía directamente e quen indirectamente, por exemplo, en función da súa idade, do seu estado civil ou de se eran homes ou mulleres.

3. Localizar, tanto espacial como temporalmente, os conflitos. Saber se se producían maioritariamente nalgunha época do ano e se había algún lugar concreto (habitual) para as loitas.

4. Coñecer a actitude dos distintos participantes. Por un lado, contrapoñer a visión dos contendentes en función da súa orixe (parroquia) e, por outro, en función do seu sexo.

5. Identificar a existencia de ritualizacións neste tipo de actividades violentas. Como se iniciaban os enfrontamentos, que armas empregaban (se é que se 
empregaban), a visión social dos que non participaban e o papel de mulleres e de homes.

6. Coñecer a época na que este tipo de acontecementos deixou de ser habitual. Situación social e económica dese momento.

7. Achar as causas máis probables da redución da violencia.

8. Saber o grao de identificación do campesiñado cos distintos tipos de entidades comunitarias nas que se podería encadrar.

9. Coñecer a participación das autoridades neste tipo de conflitos.

En conxunto, búscase que os resultados obtidos sirvan como posible hipótese de partida para futuros traballos neste campo que, dun xeito máis cuantitativo, procuren a súa demostración, xa sexan a nivel micro ou para espazos máis amplos.

\subsection{Hipóteses e supostos}

En base á reflexión sobre os estudos previos citados no estado da cuestión, os aspectos máis relevantes que se considera probable obter con esta investigación concreta (servirán como base orientadora de partida para a mesma) son os que a seguir se enumeran:

1. As causas de violencia que se esperan atopar son as derivadas da competencia polos recursos (uso dos comunais, a caza ou aproveitamento das augas de regadío) e a competencia por conseguir muller. É dicir, dar solución a dous obxectivos básicos dos seres vivos, por un lado a supervivencia do propio individuo e por outro a transmisión da carga xenética propia.

2. A participación en actos violentos deste tipo espérase que estea restrinxida aos homes e, máis concretamente, aos mozos.

3. A localización espacial dos conflitos probablemente se atope nos campos das festas e nos territorios de disputa de recursos (comunais). No tocante ao tempo, pénsase que as primeiras terán lugar en datas concretas (cando haxa as festas) e as segundas distribuídas ao longo de todo o ano.

4. Agárdase que, ante posibles ameazas "foráneas", exista unha actitude favorable cara á defensa da entidade comunitaria común por parte de todos os membros da mesma.

5. No tocante á ritualización, é probable que non exista, que os enfrontamentos sexan froito de detonantes puntuais, como por exemplo, o conflito por unha muller, e que gañen magnitude en función de altercados anteriores que envolveran aos participantes.

6. Espérase que o momento de redución destes enfrontamentos coincida cos procesos de emigración masiva (finais dos anos cincuenta e década dos sesenta). 
7. Como causas de redución da violencia agárdase identificar a redución drástica do número de mozos nas distintas parroquias, por mor da emigración (indicada no punto anterior).

8. No tocante á identificación dos campesiños coas distintas entidades comunitarias, espérase que exista unha maior vinculación coa parroquia que co concello. Pois a existencia destes era moito máis recente, década de 1830 , que a de aquelas, que se remontaría á Idade Media.

9. Con respecto á participación das autoridades nos conflitos, agárdase que o recurso a elas fose moi escaso; que o campesiñado procuraría solucionar os seus conflitos por outros camiños (entre eles), sen acudir a axentes exóxenos.

\subsection{Deseño da investigación}

O proceso de deseño da investigación orientouse dentro dunha metodoloxía hipotético-dedutiva. Así, en primeiro lugar realizouse unha aproximación á realidade da cuestión por medio da revisión de estudos de temática similar e outra bibliografía relacionada cos obxectivos propostos. Unha vez realizado este primeiro paso, e co fin de dar resposta aos citados obxectivos, deséñanse unha serie de instrumentos de recollida de datos (para empregar no traballo de campo), destinados á obtención posterior, previa a súa análise, dunha teoría.

O estudo toma como base principal o caso concreto dos enfrontamentos entre dúas aldeas colindantes do sueste de Ourense (moi coñecida a súa antiga inimizade nas zonas próximas): San Pedro de Pousada (parroquia de San Miguel de Progo), no concello de Riós, e Moialde (parroquia de Santa María de Moialde), no concello de Vilardevós. Sendo o período obxecto da investigación tres décadas (40, 50 e 60 do século XX). O seu emprazamento é o que se observa nas figuras 1 e 2 .

A información obterase por medio de tres técnicas que se complementan: unha entrevista con base no modelo semiestruturado, un cuestionario autoadministrado e a recollida de datos durante a realización da entrevista, baseándose, neste último caso, fundamentalmente na observación de aspectos subxectivos como a linguaxe non verbal. Mesturando deste xeito o emprego de métodos cualitativos (entrevista e observación) con cuantitativos (cuestionario).

En primeiro lugar, con respecto á entrevista hai que mencionar que se opta por este tipo (con base no modelo semiestruturado) por ser máis adaptable a propia evolución da conversa. Formalmente consta de tres grandes grupos (temáticas) de preguntas: Aspectos persoais (tratan, por exemplo, idade, lugar de nacemento, se emigrou ou cantos anos tiña ao casarse); Aspectos Sociais (por exemplo, o funcionamento das herdanzas, o proceso de cortexo e casamento ou 


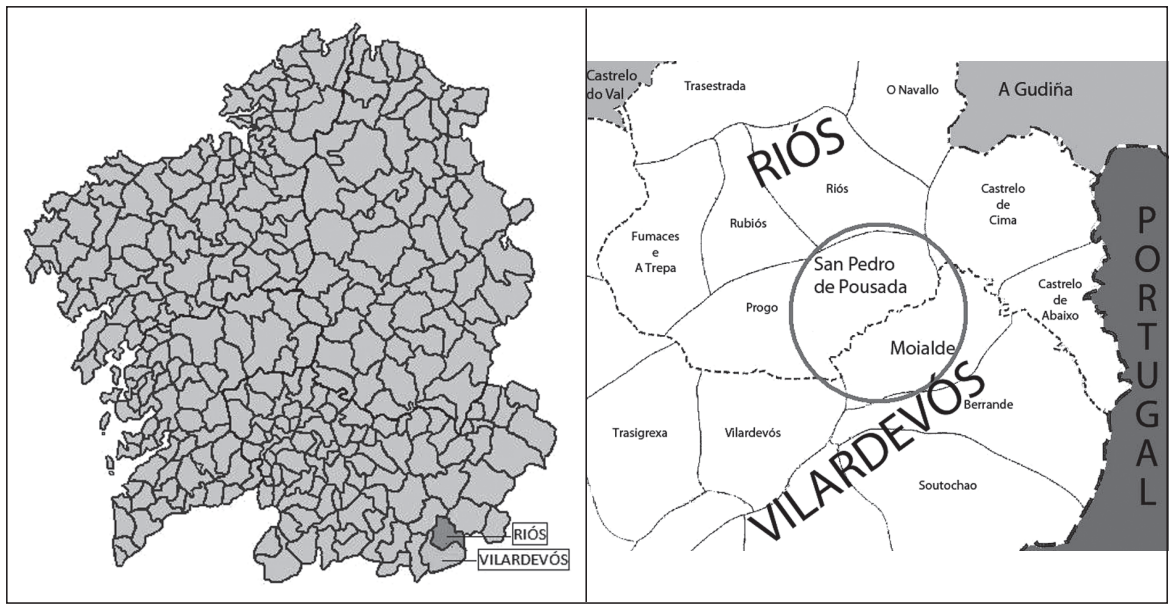

Figura 1. Mapa da localización dos concellos de Riós e Vilardevós. Elaboración propia a partires do ofrecido na Wikipedia.
Figura 2. Mapa das parroquias da zona.

Elaboración propia a partires do material cartográfico ofrecido na web oficial do Concello de Riós.

de que tipo de actividades lúdicas dispuñan) e Conflitividade (este sería o bloque máis directamente relacionado cos obxectivos da investigación. Nel abordaríanse aspectos como os tipos de conflitos, quen participaba neles, as súas causas e a súa evolución). Non obstante, estas cuestións son flexibles, é dicir, o que figura na guía empregada son uns enunciados de preguntas, pero estas non se realizan de forma ríxida, todo isto co obxectivo de xerar un ambiente relaxado no que os entrevistados poidan manifestar mellor as súas opinións. Para a elaboración do modelo empregado como guía seguíronse as propostas recollidas en varios textos ${ }^{12}$. Formalmente realizouse un total de seis entrevistas, cinco colectivas e unha individual. Nas colectivas participaron 5 matrimonios (dous de cada unha

\footnotetext{
${ }^{12}$ Os máis destadados son os seguintes: Andrés Arias e Baltasar Fernández Ramírez, "La encuesta como técnica de investigación social”, en Antonio José Rojas, Juan Sebastián Fernández e Cristino Pérez (Eds.), Investigar mediante encuestas. Fundamentos teóricos y aspectos prácticos, Madrid, Síntesis, 1998, páxs. 31-49; Andrés GonzÁlez Gómez e José Luis PAdilla, "La entrevista", en Antonio José Rojas, Juan Sebastián Fernández e Cristino Pérez (Eds.), Investigar mediante encuestas. Fundamentos teóricos y aspectos prácticos. Madrid, Síntesis, 1998, páxs. 141-153; Vicente G. Manzano, Antonio José Rojas e Juan Sebastián Fernández, Manual para encuestadores, Barcelona, Ariel, 1996; José Luis Padilla, Andrés González Gómez e Cristino Pérez Meléndez "Elaboración del cuestionario", en Antonio José Rojas, Juan Sebastián Fernández e Cristino. Pérez (Eds.), Investigar mediante encuestas. Fundamentos teóricos y aspectos prácticos, Madrid, Síntesis, 1998, páxs. 115-140.
} 
das aldeas en cuestión e un terceiro doutra), na individual tamén se tratou dunha persoa dunha aldea distinta.

En segundo lugar, no tocante ao cuestionario autoadministrado, destacar que consta de tres partes: as dúas primeiras teñen por obxectivo coñecer o grao de identificación do campesiñado coas distintas unidades poboacionais nas que se poden inscribir ( pueblo -termo empregado na variade dialectal desta zona para referirse aos núcleos de poboación que noutras partes de Galicia poderían ser denominados como aldeas ou lugares. É probable que este tipo de asentamento sexa unha continuación de asentamentos castrexos. Así o fai pensar o emprazamento de varios deles (zonas elevadas de fácil defensa) e a toponimia (Castrelo de Cima, Mourisco, Castrelo de Abaixo, O Castrillón ou a Cavanca dos Mouros)-, parroquia, concello, provincia, Galicia e España); a primeira destas dúas fundaméntase en estudos de psicoloxía sobre a identidade ${ }^{13}$; a segunda baseada no "tipo Likert"14, este modelo caracterízase pola existencia de ítems negativos e positivos sobre unha mesma cuestión dispostos en número similar, podendo o suxeito responder entre 5 variables: "Moi de acordo", "De acordo", "Nin de acordo nin en desacordo", "En desacordo”, "Moi en desacordo”. Cada un dos ítems ten un valor, de xeito que os que teñan unha actitude máis favorable obterán unha puntuación máis alta. Non obstante, este modelo só foi seguido en parte, así mantivéronse as variables pero non se introduciron todos os ítems negativos e positivos. Finalmente, a terceira parte consta de dúas preguntas (causas deste tipo de violencia -intercomunitaria- e causas da finalización da mesma) que pretenden, en base a unhas causas dadas (coa posibilidade de introducir outras), que o entrevistado ou entrevistada as puntúe de 0 a 10, en función das que, na súa opinión, tiveran unha maior ou menor incidencia no fenómeno estudado.

Finalmente, como último instrumento de recollida de datos empregado na investigación, utilizouse o derivado da anotación, despois das entrevistas, de datos máis ou menos subxectivos baseado nas manifestacións realizadas e fundamentalmente na linguaxe non verbal (movementos, xestos ou mirada) e na linguaxe para-verbal, por exemplo, ritmo, ton, acento, volume ou fluidez.

$\mathrm{O}$ estudo realizouse sobre unha mostra que incluía un total de 11 persoas (seis mulleres e cinco homes), catro matrimonios (dous de cada unha das aldeas en loita, San Pedro de Pousada e Moialde) e unha quinta persoa e un matrimonio que actuaría como entrevistas de control, que non serían de ningunha destas dúas aldeas, pero si de lugares próximos, que, polo tanto, coñecendo os feitos, poderían achegar unha visión máis imparcial.

\footnotetext{
13 Ángel Gómez Jiménez, "Las raíces de la violencia en la adolescencia. Cuando el individuo está fusionado con el grupo", en Hacia una protección integral del menor: XIX Seminario "duque de Ahumada", Madrid, Ministerio del Interior, 2008, páxs. 13-36.

14 J. L. Padilla, A. González Gómez e C. Pérez Meléndez, “Elaboración...”, páxs. 136-138.
} 
Estatisticamente, para o caso de Moialde os entrevistados representan o 10,00\% dos actuais residentes nesa aldea maiores de 70 anos e, con respecto a San Pedro de Pousada, constitúen o 13,79\% dos maiores de 65 .

O proceso en si de recollida de datos divídese en varias etapas, as cales se explican brevemente a continuación:

Primeiramente, a modo de introdución, realízase unha breve explicación que ten por obxectivo expoñer en que vai a consistir a actividade: realización dunha entrevista e dun cuestionario. Con respecto á entrevista exponse cal vai a ser a dinámica (realización de preguntas e posterior contestación e a orde xeral dos grandes bloques temáticos, indicando que os mesmos non son ríxidos, é dicir, que se pode saltar duns aos outros). Igualmente, tamén se dan a coñecer, a modo de exemplo, algunhas das preguntas que se van a enunciar, explicando que van a ser gravados (feito para o que xa deran o seu consentimento cando se realizou a concertación da cita). Finalmente, no tocante á entrevista, indicar que o idioma empregado polo entrevistador será o galego (coas variantes dialectais propias desa zona), pois os entrevistados será o que empreguen, facilitando así que estean o máis cómodos posibles. Con respecto ao cuestionario, a súa explicación déixase para despois de ter realizada a entrevista co obxectivo de que as instrucións sexan o máis recentes posibles á súa realización, neste primeiro momento só se indica que se realizará ao finalizar a entrevista, pero sen entrar en máis detalles.

En segundo lugar, iníciase a entrevista que, como xa se mencionou, non contén unhas preguntas ríxidas, senón que xogan un papel máis flexible, así en función das contestacións dos entrevistados introdúcense outras ou pídense aclaracións. Unha vez finalizada a entrevista, déixase un breve espazo de tempo, para comentar o que queiran os entrevistados, pois é normal que despois de deixar de gravar se sintan máis libres para realizar outras manifestacións e aclaracións.

Despois de rematado o período de charla sen gravar, pásase á explicación de cómo cumprimentar o cuestionario, indicándoselles que na súa cumprimentación axudaráselles solucionando cantas dúbidas lles xurdan.

Finalmente, unha vez rematado todos estes procesos (despois da despedida na que se lles agradece aos entrevistados e entrevistadas a colaboración prestada), e sen a presenza dos participantes, procédese á anotación das observacións de carácter máis subxectivo (terceiro método de recollida de datos) e aqueles aspectos que foron relatados fóra da gravación. 


\section{ANÁLISE DE RESULtAdos}

\subsection{Contextualización xeográfica e social}

Os pueblos (aldeas) obxecto da análise, San Pedro de Pousada e Moialde, atópanse nunha zona de montaña ao leste do val de Monterrei. O primeiro no concello de Riós e o segundo no de Vilardevós. A nivel parroquial Pousada forma parte de San Miguel de Progo (Vilariño das Touzas, Progo, Santa Baia e Pousada) e Moialde, que é cabeceira de parroquia, de Santa María de Moialde (Santa Comba e Moialde).

Os pueblos están formados por agrupacións de casas. As casas son a unidade básica de explotación campesiña; normalmente cada casa era habitada por unha familia (familia nun sentido amplo, pois podían vivir varias xeracións, incluíndo irmáns cos seus respectivos cónxuxes e fillos).

As parroquias, entidades de orixe relixiosa, están constituídas por un ou varios pueblos. Na actualidade, este tipo de entidade non ten un recoñecemento como unidade administrativa pero gozan dunha arraigada tradición que vén de varios séculos. Así, por exemplo, na Constitución de 1812 estipulábase como unha das circunscricións electorais a parroquia; no estatuto de autonomía de Galicia de 1936 (foi plebiscitado afirmativamente polos galegos pero non chegou a entrar en vigor por mor da Guerra Civil), no seu artigo 14 indicábase: "Corresponde a la Región gallega: a) La organización y régimen local de Galicia, sobre las bases de reconocimiento de personalidad jurídica a la parroquia rural [...]"; ou no actual estatuto de autonomía, de 1981 ${ }^{15}$, Artigo 27.2 “[...] correspóndelle á Comunidade Autónoma galega [...] 2. Organización e réxime xurídico das comarcas e parroquias rurais como entidades locais propias de Galicia [...]" e no artigo 40 "[...] por lei de Galicia poderase: [...] 3. Recoñecer personalidade xurídica á parroquia rural" (neste caso, aínda que a norma legal está vixente, estes preceptos non se concretaron nun recoñecemento como unidade administrativa).

Estes dous pueblos teñen un tipo de poboamento concentrado, de caserío denso, que se caracteriza por ter as rúas moi estreitas e as casas apiñadas. Neste tipo de zonas este é un dos máis habituais, xunto ao polinuclear de caserío denso, que basicamente é igual que o anterior, pero o poboamento vese dividido por accidentes xeográficos como ríos ou barrancos que dificultan a súa completa unidade ${ }^{16}$.

O seu emprazamento é o que se pode ver na Figura 3, sendo a zona marcada cunha elipse un monte comunal que estaba en disputa. Os habitantes de Moialde afirmaban que o seu dominio chegaba ata o río e os de Pousada dicían que ía

\footnotetext{
${ }_{15}$ Lei orgánica 1/1981, de 6 de abril, do Estatuto de Autonomía para Galicia (BOE 28/04/1981).

${ }^{16}$ Xosé Ramón Mariño Ferro, Antropoloxía de Galicia, Vigo, Xerais, 2000, páxs. 21-24.
} 


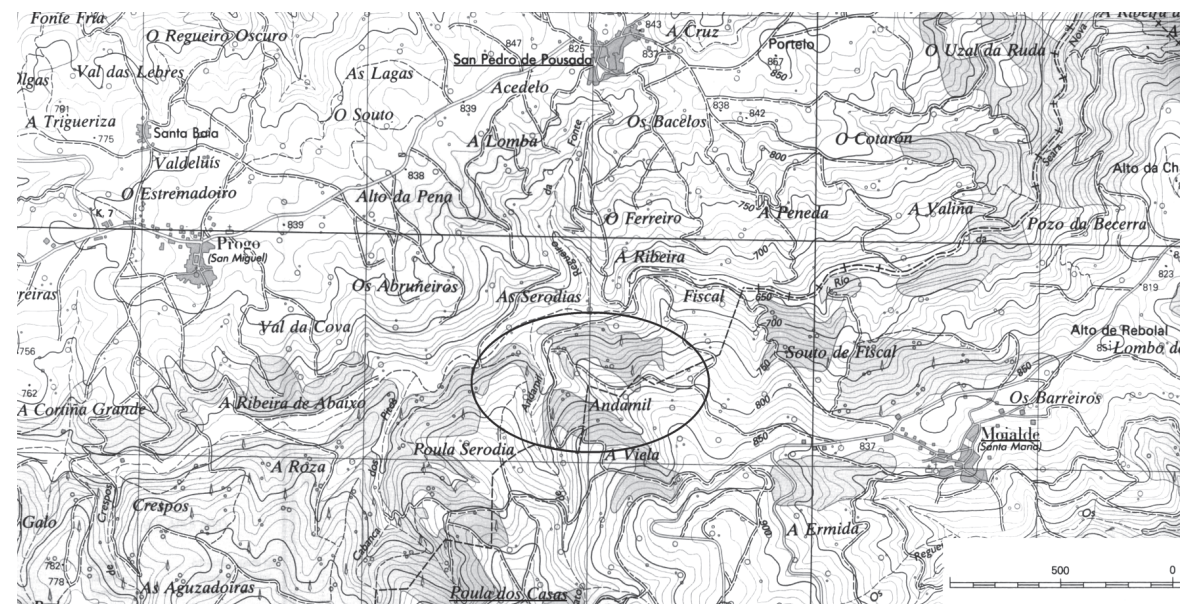

Figura 3. Mapa de elaboración propia en base ao Mapa Topográfico Nacional de España; Riós 303-II; (16-25). Orixinalmente con escala 1:25.000.

máis arriba, aproximadamente un pouco máis aló do límite do actual concello de Riós (marcado por unha liña descontinua que ao coincidir co río se combina con cruces).

As comunidades campesiñas asentábanse nas relacións de solidariedade, en primeiro lugar dentro da familia e despois dentro do propio núcleo de poboación. Isto debíase a que para a realización de determinados traballos, como a sega ou a malla (deben ser realizados nun espazo curto de tempo) era precisa máis man de obra que a que dispuña unha soa casa. Así, existía un sistema coñecido como tornaxeira, consistente nunha rede solidaria de axudas mutuas á hora de realizar este tipo de traballos ou no caso de asistencia por enfermidades ou mortes. Isto, en conxunto, favorecía a creación dunha identidade grupal moi forte en contraposición aos foráneos.

As familias obtiñan os seus recursos da explotación de bens propios (eran pequenos propietarios) e dos comunais. Estes últimos eran fundamentais para complementar as necesidades de subsistencia. O comunal podía ser de varios tipos: monte de veciños (de orixe xurídica xermánica: todos os veciños tiñan acceso a eles polo único feito de seren veciños, pero só mentres mantivesen esta condición); montes de voces ou varas (de tradición xurídica romana: a este tipo de monte non tiñan acceso por igual todos os membros da comunidade, podíase dar o caso de que uns puidesen acceder a unha menor extensión ou só para actividades como o pastoreo, pero non para a recollida de leña); finalmente, os montes privados (derivados dunha adquisición por parte de todos os veciños; de orixe 
moito máis recente $)^{17}$. No caso concreto destes pueblos tratábase dun monte de veciños (o primeiro caso).

\subsection{Causas dos conflitos}

Do estudo das entrevistas e dos cuestionarios conclúese que as causas habituais deste tipo de violencia situábanse nas festas (por motivo de amoríos) e na competencia polo acceso aos recursos comunais. Estas dúas causas son citadas polos distintos estudos que, referidos a Galicia, tratan este particular.

No primeiro dos casos hai que ter en conta o contexto social, no que, debido á escasa tecnificación, o sistema de produción descansaba na forza de traballo biolóxica. Polo tanto, para poder sobrevivir, especialmente na vellez, precisábase de fillos ${ }^{18}$. Ademais, estaba a cuestión moral de ser preferible ter fillos dentro do matrimonio (especialmente para as mulleres, aínda que o feito de que os tivesen sen estar casadas non era unha condena social absoluta, si que reducía as súas posibilidades de contraer nupcias). Pois, non hai que esquecer que o matrimonio era a forma habitual, e a socialmente aceptada, de creación de novas familias.

Cousa distinta era o establecemento dun novo fogar, xa que isto non sempre era fácil, pois para construír unha nova casa era preciso dispoñer de fondos suficientes, moi difíciles de conseguir por medio dos excedentes agrícolas obtidos con só parte da herdanza (podían, se se independizaban, recibir, provisionalmente unha parte da herdanza para poder sobrevivir. Esta parte volvería, unha vez falecidos os pais, a ser repartida entre os distintos irmáns, é dicir, que un dos herdeiros cultivase unha parcela determinada non aseguraba que esta finalmente pasase a ser propiedade do mesmo. O habitual nesta zona, no tocante á herdanza, era que esta fose igualitaria entre todos os fillos e fillas do matrimonio, coa posibilidade dunha pequena mellora para quen se encargase de coidar dos pais -que podía recibir a casa paterna-). Deste xeito, como se desprendeu das entrevistas, non era raro que os cónxuxes continuasen a vivir, cada un na casa dos seus respectivos pais. Isto é o que se coñece como residencia natolocal ${ }^{19}$ ou que fosen para a dos pais dun dos cónxuxes; esta última posibilidade dependía da situación previa dos respectivos pais (número de bocas que alimentar, dispoñibilidade de terras, forza de traballo coa que contaban ou predisposición dos mesmos eran os condicionantes máis influentes).

Por este motivo, as unións entre persoas do mesmo núcleo (se tiña capacidade demográfica suficiente) ou de núcleos próximos (se non había suficiente

\footnotetext{
${ }^{17}$ X. R. Mariño Ferro, Antropoloxía de..., páxs. 284-287.

${ }^{18}$ P. SaAvedra Fernández, La vida cotidiana..., páx. 238.

${ }^{19}$ X. R. Mariño Ferro, Antropoloxía de..., páx. 339.
} 
poboación) era o máis habitual, xa que facilitaba a explotación das terras (medio fundamental de subsistencia). No caso de cónxuxes que procedesen de lugares alonxados terían que valerse de cambios ou vendas, desprendéndose das propiedades da zona na que non ían a residir (este procedemento tiña o inconveniente de atopar a xente disposta a vender ou cambiar ${ }^{20}$. Ademais, tamén era beneficioso para os pais, pois aumentaban as súas posibilidades de ter axuda no futuro, cando fosen vellos.

Así, por un lado temos o que poderíamos definir como endogamia parroquial, que a súa vez se mestura coa homogamia (matrimonio con persoas do mesmo ou similar nivel social) ${ }^{21}$, pois non eran ben vistos os enlaces entre persoas de orixe económica moi dispar.

As mulleres son presentadas como unhas das causantes dos enfrontamentos ao quedar con varios mozos á mesma hora e no mesmo lugar. Isto é indicado tanto por mulleres coma por homes. Esta actitude debe ser entendida como unha arma da que dispuñan as mulleres para poder escoller o esposo que lles resultase máis adecuado (o máis forte, o máis intelixente, etc.). Ao igual que os homes xogaban a baza de dificultar o acceso de homes foráneos ás mozas do pueblo, para aumentar así as súas posibilidades de matrimonio, as mozas tiñan outros medios para aumentar a oferta de candidatos. Un exemplo disto represéntano os códigos empregados para avisar aos mozos doutras aldeas da celebración de festas improvisadas (fóra das datas habituais), consistentes, por exemplo, en prender fachóns de palla en altos de montes que tiñan visión directa coa aldea dos que se pretendía atraer ou preguntar, a berros (dende certa distancia), se nesa aldea atoparan cabras ou ovellas que se lles perderan. Polo tanto, as mulleres non eran un suxeito pasivo nestes eventos, que poderían ser incluídos dentro do cortexo.

En resumo, era moi importante tanto para mozos como para mozas poder contraer matrimonio con cónxuxes que fosen do máis preto posible. As actitudes de uns e outros a este respecto eran distintas. Por un lado, para os mozos as mulleres do pueblo pasaban a ser un ben da comunidade que había que protexer dos foráneos; isto facía, que os mozos que intentasen cortexar a unha moza contasen coa oposición, xa fose aberta ou velada, dos mozos nativos da aldea da moza en cuestión. Por outro lado, que un mozo mocease cunha moza doutro lugar non contaba coa oposición dos seus veciños pero si cos da moza (deixaba de ser competencia para uns e pasaba a sela para outros). Mentres tanto, as mulleres buscaban que a oferta de mozos non se reducise a súa propia aldea. Polo tanto, o conflito entre mozos de distintos pueblos estaba servido.

\footnotetext{
${ }^{20}$ P. SaAvedra Fernández, La vida cotidiana..., páx. 212.

${ }^{21}$ X. R. Mariño Ferro, Antropoloxía de..., páx. 326.
} 
Por outra banda, como xa se indicou para formar unha nova casa, os medios dos que dispuñan as familias para subsistir eran moi xustos. Por iso, era habitual valerse dos bens comunais, constituíndose estes como un apoio indispensable para a supervivencia familiar. De aí a acérrima defensa que facían os veciños destes bens cando os consideraban en perigo pola intromisión de foráneos.

O monte comunal era empregado de varios xeitos, sendo os máis destacados os seguintes: obtención de estrume (folla -de árbores como o castiñeiro ou o carballo-, xestas, toxos ou carqueixas) que, xunto con palla e herba, mesturado e modificado (descomposto) pola súa combinación coas deposicións dos animais estabulados, aos cales lles servía de cama (tamén enchendo as fochancas das rúas), eran os compoñentes fundamentais do esterco (abono); lugar de pastoreo; fornecedor de leña e lugar onde provisionalmente se podían explotar novas leiras.

Para este caso concreto, dos usos antes mencionados os conflitos máis comúns eran debidos aos aproveitamentos para pasto, leña e estrume. A apertura de novas leiras en territorios en conflito non era habitual. Pois, a pesar de que os apresamentos de parte destes montes comúns foi unha práctica numerosa en Galicia nos séculos XIX e parte do XX (froito da indefensión xurídica na que se atopaba nesa época a propiedade colectiva); nestas condicións conflitivas, non só se contaba coa potencial oposición dos veciños da propia aldea (se se trataba dun uso non consentido), senón coas máis que probables represalias dos da aldea en disputa. Feito que dificultaría os traballos de cultivo e non garantiría a recollida da colleita (roubo, sabotaxe).

Continuando co caso concreto que serve como fonte desta investigación, todo indica que o conflito polo terreo comunal viña de vello. Así, por exemplo, no Catastro de Ensenada, mediados do século XVIII, no tocante aos límites do coto (pregunta 3) e aos bens comúns (pregunta 23) ${ }^{22}$ vense coincidencias. Nos dous casos un dos límites é un monte común, chamado Andamil, e os dous pueblos o relacionan como parte das súas respectivas terras comunais.

Pregunta 3. Qué territorio ocupa el término, cuánto de levante a poniente y del norte al sur, y cuánto de circunferencia, por horas, y leguas, qué linderos o confrontaciones; y qué figura tiene, poniéndola al margen.

[Moialde:] A la tercera dixeron $q[\mathrm{ue}]$ el termino de esta $F$ [eligresía] [...] al Norte confina con monte común, llamado, andamil del

\footnotetext{
${ }^{22}$ Ministerio de Educación Cultura y Deporte, Portal de Archivos Españoles (PARES), "Interrogatorio de la Feligresía de San Miguel de Progo y mas cotos e Interrogatorio de Santa María de Moyalde" [en línea], disponible en < http://pares.mcu.es > [Consulta: 02/03/2015].
} 
lugar de San Pedro de Pousada de la F[eligresía] de San Miguel de Progo [...]

[San Pedro:] A la tercera digeron que el termino [...] Y el coto de san Pedro de Pousada [..] confina [..] al medio dia con monte comun llamado andamil de la F[eligresía] de santa María de Moialde [...] Pregunta 23. Qué propios tiene el común y a que asciende su producto al año, de que se deberá pedir justificación.

[Moialde:] A la veinte y tres digeron, que el común de esta F[eligresía] no tiene rentas ni propios algunos, a excepción de un monte llamado andamil [...] N[orte] monte común llamado andamil de la F[eligresía] de San Miguel de Progo [...]

[San Pedro:] A la veinte y tres digeron que el común de cada uno de dichos Cotos [Feligresía de San Miguel de Progo] no tienen rentas ni propios algunos a excepción [...] Otro llamado Andamil y Balcobo el que perteneze al común del coto de san Pedro de Pousada [...] L[evante] confina con tierras labradias llamadas Sequeiros de la Feligresía de Santa María de Moialde [...] M[ediodia] con monte común llamada andamil de la F[eligresía] de santa María de Moialde [...]

No eido das lendas temos outro indicio disto. Tanto os habitantes de Moialde como os de Pousada atribúen o inicio da disputa por ese monte a unha historia con varias versións en función do pueblo, que sempre teñen en común: a existencia de dúas irmás, unha tiña un fillo e a outra non (que nalgunha versión son as fundadoras dos distintos pueblos; similitude con Rómulo e Remo); que vivían nun lugar denominado A Poula das Casas (un posible asentamento castrexo); por mor dunha invasión de formigas tiveron que mudarse; cada unha decidiu ir para un monte distinto, chegando ao acordo de que a que primeiro tocase unha campá quedaría co territorio en disputa; no camiño cara aos seus respectivos destinos a que tiña o fillo tivo que deterse a lavar (a roupa do neno ou ao propio neno, en función das versións) polo que a outra chegou primeiro, a Pousada, e tocou a campa; quedando, deste xeito, as terras para os de San Pedro de Pousada.

A variación fundamental da historia en función da orixe dos que a contan atópase no seguinte: para os de Moialde, a parada da irmá que se dirixía a súa propia aldea foi debida ás súas obrigas materno-filiais (é presentada como unha nai entregada ao seu fillo); para os de Pousada, esa irmá detívose a lavar porque a outra, a que se dirixía a San Pedro, era coxa, polo que, sumando isto a que a distancia que tiña que percorrer era maior, esperaba que esta nunca chegase a tempo. Os de Moialde en ningún momento din que unha das irmás era coxa. Así, 
nesta versión mestúranse trazos da fábula da lebre e a tartaruga de Esopo. En resumo, cada aldea pretendía xustificar moralmente a súa reclamación.

Neste tipo de enfrontamentos son habituais as mortes de cabezas de gando (se estas eran descubertas a pacer no territorio en disputa). Tamén era habitual a incautación de parte do gando, que só podía ser rescatada previo pago dunha cantidade compensatoria (se o feito tiña lugar entre veciños do mesmo pueblo érase máis benevolente). Un exemplo desta costume vén recollido no tratado de fronteiras entre España e Portugal de 1864, que no seu artigo $29^{23}$ viña a regular o que parece ser unha práctica habitual:

A fin de evitar en lo posible los daños que puedan ocasionar á los pueblos fronterizos con motivo de prendimientos de ganados, y para mantener la mejor armonia entre los mismos pueblos, se conviene:

$1^{\circ}$. Que en el hecho de entrar ganado á pastar indebidamente en territorio de otra nación no se imponga sinó penas pecuniarias;

$2^{\circ}$. Que para responder de las penas y de los gastos, que se originen, no pueda retenerse mas de una res por cada diez de las aprehendidas.

Outros conflitos intercomunitarios derivaban da utilización das augas de regadío, pero, a diferenza do caso dos comunais, que pertencían a todo o pueblo, estas só pertencían a un número determinado de veciños que eran os que se enfrontaban aos que eles puidesen considerar usurpadores do seu uso. Polo tanto, esta causa só é en parte intercomunitaria, pois si que podía levar ao enfrontamento entre veciños de distintas aldeas (como no caso de abrir preseiras nos ríos), pero non enfrontaban ao conxunto das poboacións.

Outras causas como o prestixio (saber quen é o máis forte) ou a caza (na actualidade existe unha grande afección cinexética na zona) parece que tiveron unha incidencia moito menor. No caso das pelexas por prestixio, poderíamos citar a Loita, un deporte consistente en medir as forzas dous homes (pero sempre cunhas regras que impedían facerse dano e nunca participaban máis de dúas persoas). No que se refire á caza, parece ser que esta costume era minoritaria e que a riqueza animal era suficiente para todos.

En resumo, tal e como se ve no Gráfico 1, derivado das respostas aos cuestionarios (media de puntuación de 0 a 10), as causas, que entrevistados e entrevistadas

\footnotetext{
${ }^{23}$ Tratado de limites entre Portugal e Hespanha assignado em Lisboa pelos respectivos plenipotenciarios aos 29 de setembro de 1864 [en línea], disponible en < http://google.es/books?id=J7gMAAAAYAAJ\&hl=es $>$ [Consulta: 02/03/2015].
} 
Gráfico 1. Causas da violencia.

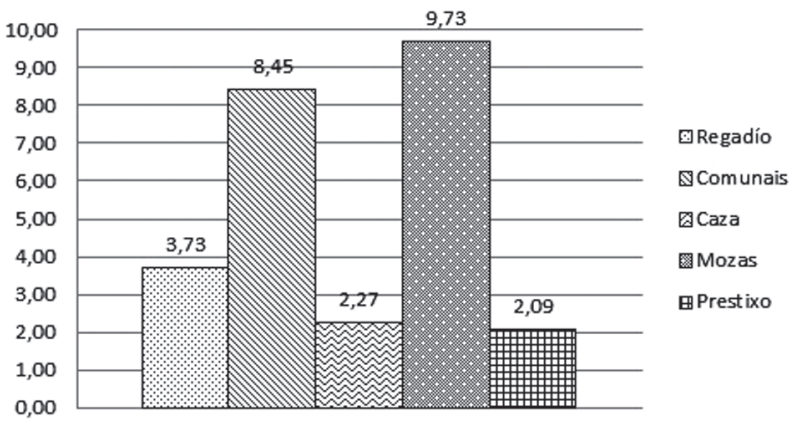

consideran como principais, orixinábanse en satisfacer necesidades básicas do ser humano. Por un lado, a reprodución (mozas) e por outro, a supervivencia (uso dos bens comunais ou o feito de poder traballar as terras próximas). A terceira en importancia (a moita distancia), o regadío, pódese englobar xunto ao uso do comunal, como defensa dos recursos (aínda que como se indicou non envolvía a todos os membros da comunidade).

\subsection{Participantes}

A este respecto hai que distinguir entre dous tipos de enfrontamentos. Se se trataba de enfrontamentos por cuestión de mozas, a loita era fundamentalmente entre mozos, pero podía acabar atraendo a participación dos outros membros da comunidade por solidariedade. Esta solidariedade era maior entre os habitantes do pueblo no que tiñan lugar os acontecementos. Cabe destacar a este respecto, un incidente relatado nas entrevistas cos habitantes orixinarios de Pousada (sentimento de ser invadidos). Despois dun primeiro enfrontamento cos mozos da aldea de Progo (da mesma parroquia) estes retiráronse para reagruparse, decidindo a continuación atarse un pano na cabeza para diferenciarse dos outros e volver á carga sen ferirse entre eles na liorta. Algún dos entrevistados, como testemuña directa, viu como os homes (despois de descubrir as intencións dos foráneos) colleron distinto tipo de armas improvisadas (utensilios agrícolas) e bloquearon todos os accesos á aira da festa, facéndoos desistir da súa actitude agresiva.

Por outra banda, se o enfrontamento tiña lugar por cuestións de comunal acudían directamente todos os homes capaces, non eran o detonante os mozos, senón que xa acudían todos xuntos. Aquí a causa sería o uso por parte dos habitantes da outra aldea daqueles bens e espazos que se consideraban de titularidade do pueblo. 
As mulleres, nenos e anciáns non participaban nos grandes enfrontamentos. Porén, si se producían, no caso dos nenos, uns primeiros enfrontamentos cos dos outros pueblos, consistentes en tirarse pedras uns aos outros, fundamentalmente nas festas, cando ían pastorear ou, no verán, cando ían ao río a bañarse. Sen embargo, tamén hai que indicar que as crianzas eras respectadas polos maiores; neste sentido, son destacables varios relatos onde se destaca que cando se producían "incautacións" ou mortes de animais, os pastores (cativos) non sufrían danos.

Finalmente, indicar que os conflitos por cuestión de mozas podían ser cos mozos de calquera pueblo dos arredores. Porén, os conflitos polo uso dos comunais era moito máis restrinxido, só cos limítrofes. Isto facía, que as inimizades entre os seus habitantes fosen maiores, motivadas en agravios anteriores.

\subsection{Lugares e datas dos enfrontamentos}

Novamente neste aspecto dáse unha diferenciación entre os enfrontamentos das festas e os do comunal. Así, no caso das festas, era habitual que a loita tivese lugar no emprazamento do baile. Sendo na maior parte das veces as datas coñecidas por todos (festas dos padróns ou datas sinaladas como Reis ou o Entroido). A pesar do anterior, os enfrontamentos podían desprazarse, neste sentido, destaca un dos incidentes relatados que se deu entre os de Moialde e os de Progo, os mozos do primeiro foron perseguindo aos do segundo ata que estes atoparon refuxio en casas dun terceiro pueblo (Santa Comba). Noutro caso, os mozos de dous lugares distintos (Berrande e Lamasdeite), tamén cunha inimizade ancestral, querían pelexar na festa de Moialde, porén, como a Garda Civil descubriu as súas intencións, requisando e destruíndo navallas e bastóns, frustráronse os seus plans; ante a imposibilidade de pelexar aí, acabaron por enfrontarse no camiño de regreso aos seus respectivos pueblos.

No caso dos enfrontamentos polos bens comunais o emprazamento era o propio lugar en disputa e, aínda que non, non había unhas datas exactas marcadas no calendario, eran máis habituais nos momentos nos que se realizaba o aproveitamento deses bens. Pois, non hai que esquecer que o tempo agrícola é cíclico e cada tipo de tarefas teñen unha época do ano propia para seren realizadas.

\subsection{Ritualización}

Existía unha ritualización nos conflitos que tiñan como causas as mozas, que se circunscribiría dentro do que sería o cortexo. Pois, sabíase que con toda probabilidade habería conflitos nas festas e xa ían todos os do pueblo xuntos (esperando na entrada da outra aldea para entraren todos a unha, homes, mulleres, nenos, etc.). Ademais, tratábase de datas marcadas, coñecidas por todos os habitantes da 
contorna. Levaban armas, polo tanto, debían previamente recollelas; deixábanas escondidas onde as puidesen coller en caso de necesidade. A maiores, existían unha serie de comportamentos que eran interpretados como probacións. Así, por exemplo, destacan os aturuxos ${ }^{24}$, un dos habituais nesta zona era o de "Arriba..." e o nome do pueblo do que eran. Neste sentido tamén destaca a necesidade de compensar aos mozos ${ }^{25}$, como acontecía en Moialde, se había un casamento (o mozo que se casaba tiña que invitar a viño e a outras viandas ao resto dos mozos).

Outro exemplo deste fenómeno era o xeito de actuar dos habitantes de terceiras aldeas no caso dunha pelexa entre outras. Nunha das entrevistas relatan un destes casos: o proceder consistía na reunión de todos os membros dunha mesma comunidade, mulleres e nenos colocábanse detrás e homes capaces diante con paus a modo de protección, no que recorda a unha rudimentaria formación militar defensiva.

De todas formas, a ritualización non chegaba aos extremos de aceptación das loitas de facción de Irlanda ${ }^{26}$, xa que aquelas tiñan unhas regras moito mellor definidas que incluso podían permitir que o castigo perante a xustiza fose menor, contando coa comprensión das autoridades. Polo contrario, as de Galicia, na época estudada, contaban coa oposición das autoridades (actuación da Garda Civil).

No caso das loitas polo control dos recursos, esta ritualización non existía. Tratábase dunha loita reactiva, era vista como unha invasión e como un roubo de bens da comunidade, indispensables para a supervivencia da mesma. Por iso, as armas empregadas, poderíase dicir que tiñan un carácter moito máis ofensivo (pois non é o mesmo o dano que pode causar un bastón que unha pedona, instrumento agrícola similar a unha alabarda). Ademais, tamén eran máis habituais as armas de fogo.

De todos os xeitos, nestes tipos de violencias, os campesiños raramente acudían ás autoridades ${ }^{27}$. A actuación das mesmas podía ser de oficio (era habitual que a Garda Civil se pasase polas festas) ou por denuncia. Este último feito era pouco común, só reservado a aqueles casos nos que se producían mortes ou feridas moi graves, pois como afirman os entrevistados, acudir a xustiza supúñalles uns gastos que lles resultaban difíciles de asumir.

Polo tanto, preferían intentar solucionar eles mesmos os problemas, xa fose chegando a un entendemento por intercesión ou mediación dalgún veciño ou veciña que procuraba apaciguar os ánimos en base, por exemplo, as relacións de parentesco ou amizades comúns (en moitas ocasións non se conseguía); ou

\footnotetext{
${ }^{24}$ M. Cabo Villaverde e J. M. VÁzquez Varela, “Las otras guerras...”, páx. 10.

${ }^{25}$ C. Lison Tolosana, Antropología..., páx. 79.

${ }^{26}$ C. Conley, "The Agreeable Recreation...”, páxs. 57, 60.

${ }^{27}$ M. Cabo Villaverde e J. M. Vázquez Varela, "Las otras guerras...”, páxs. 5, 11-12.
} 
devolvéndolles o agravio aos agraviadores (o ollo por ollo), opción habitual en base ás entrevistas. Así, por exemplo, para o caso concreto da loita polo comunal, non se detectan requirimentos de mediación ou arbitraxe á concellos, autoridades ou o recurso á xustiza.

\subsection{Causas da desaparición e época da mesma}

As causas que os entrevistados consideran como determinantes na finalización dos acontecementos violentos intercomunitarios, segundo a media das súas puntuación de 0 a 10, son: a emigración e as súas consecuencias e a educación. Por un lado, coa emigración, especialmente a dos anos 60, produciuse un descenso drástico da poboación de mozos nas aldeas. Outros procesos migratorios, como o de América, por ser en menor proporción, non incidiron decisivamente na eliminación dos conflitos.

A emigración permitiu contactar con outras xentes e ver as súas costumes, incluso en ocasións persoas de comunidades en conflito, como foi o caso destas dúas aldeas, emigraban a un mesmo lugar (no exemplo estudado a Ermua no País Vasco). Isto fixo que os que antes eran inimigos acabasen por facer fronte común, por exemplo, nas reivindicacións laborais nas empresas nas que traballaban.

Tamén se menciona a educación, á que a seguinte xeración tivo acceso de xeito case unánime, por medio da cal, unha nova conciencia (a do Estado) esténdese, xa non só por medio do uso da forza coercitiva senón tamén grazas a formación académica, acabando por desprazar costumes arraigadas da sociedade rural. Así, neste caso concreto, influirían en parte as proposicións de Steven Pinker ${ }^{28}$, relacionadas co Leviatan de Hobbes (Estado) e coa idea do DOUX COMMERCE (a suma de esforzos ten maiores beneficios que o enfrontamento).

Gráfico 2. Causas da finalización da violencia

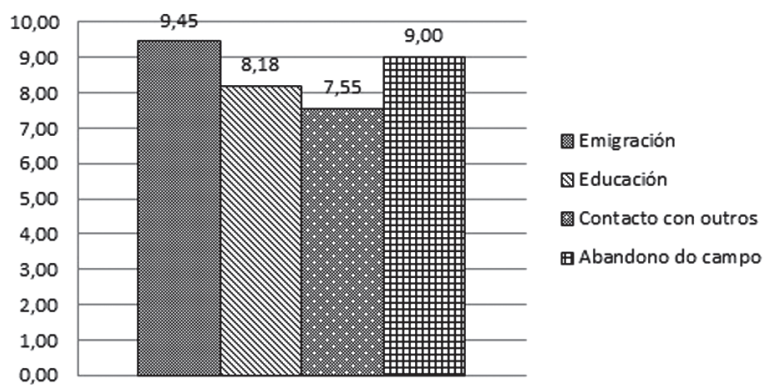

\footnotetext{
${ }^{28}$ Steven PInKer, Los ángeles que llevamos dentro. El declive de la violencia y sus implicaciones, Barcelona, Espasa, 2012, páxs. 885-890.
} 
Deste xeito, este tipo de conflitos que se clasificarían como competitivos ${ }^{29}$ (competencia por recursos e por mozas entre grupos similares), deixou de ter a súa razón de ser. Pois, o uso dos comunais xa non era indispensable para a supervivencia (moita xente foi a traballar ao estranxeiro, Suíza, Alemaña, Francia, etc., ou a zonas máis industrializadas dentro da propia España, como o País Vasco, Cataluña ou, dentro de Galicia, Vigo).

Por outra banda, co desprazamento da súa residencia podíanse relacionar con moita máis xente, polo cal o seu mercado matrimonial dispuña de maior oferta.

Estas son as causas que erradicaron, ou polo menos que fixeron testemuñal a violencia intercomunitaria. Pois, a pesar de que xa houbera procesos que produciran a súa diminución, como a maior represión e a ausencia de mozos durante a Guerra Civil; isto non foi suficiente, fixo falla unha fonda mudanza do sistema produtivo e social para que finalmente desaparecera.

\subsection{Identificación dos habitantes}

Existía entre os habitantes das distintas aldeas un profundo sentimento de pertenza a unha entidade común e diferenciada que se sustentaba en lazos de solidariedade, como os xa mencionados das axudas comunitarias da tornaxeira. Sendo esta entidade o pueblo (aldea).

A propia comunidade tiña distintas armas para axudar a que a xente fose solidaria no caso dunha ameaza externa. Por exemplo, nun dos incidentes xa mencionados (o ataque aos de Pousada no que os de Progo se atan un pano á cabeza para diferenciarse), cando un mozo do pueblo contrario quixo escapar, ao ver a situación de inferioridade numérica na que se atopaban, foi "convidado" por medio dun pau a que compartise a sorte dos seus compañeiros. Así, non só non estaba ben visto que un veciño "desertase" senón que tampouco o estaba que o fixesen os contrarios. Outra arma habitual era a retirada do saúdo, isto en comunidades de reducidas dimensións resultaba un grave problema, pois practicamente o castigado quedaba condenado a gardar silencio ata que fose novamente aceptado pola comunidade.

Xosé Ramón Mariño Ferro ${ }^{30}$ fala dunha identidade múltiple e piramidal. Piramidal no sentido de que cada individuo forma parte, ao mesmo tempo, de varios grupos que, á súa vez, forman parte doutros grupos. Para o caso galego fala de casa, aldea, parroquia, Galicia e España. A cuestión aquí é saber cal prevalece sobre as outras en caso de conflito, en especial no caso da aldea e da parroquia.

\footnotetext{
${ }^{29}$ Charles Tilly, Luise A. Tilly e Richard Tilly, El siglo rebelde, 1830-1930, Zaragoza, Prensas Universitarias de Zaragoza, 1997, páxs. 288-289.

30 X. R. Mariño Ferro, Antropoloxía de..., páxs. 362, 386-387.
} 
Gráfico 3. Identificación con entidades

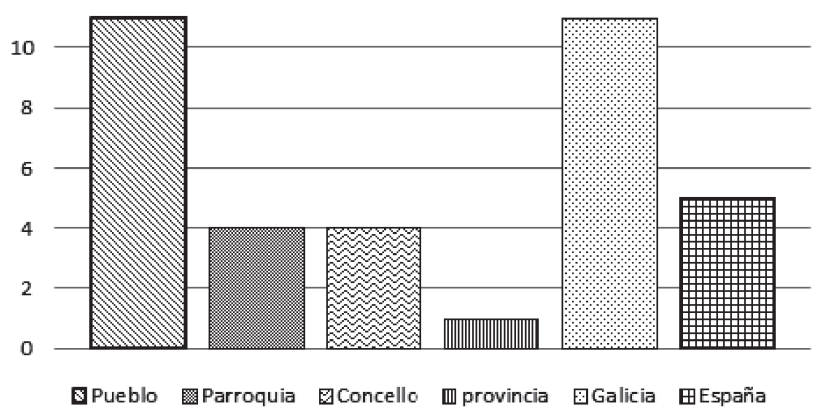

A resposta a isto, baseándose nas entrevistas e nos cuestionarios, é que, polo menos para este caso concreto, prevalece o pueblo (aldea). Pois son relatados enfrontamentos entre os distintos pueblos que formaban a parroquia, como por exemplo, entre San Pedro de Pousada e San Miguel de Progo. Outros indicadores serían os feitos de iren as festas todos os do pueblo xuntos e non cos da parroquia ou de non prestarse axuda mutua en caso de conflito.

Das distintas identidades propostas a que menos aceptación tiña era a provincia, logo ao mesmo nivel atopábase a parroquia (cunha identidade maior en Moialde, posiblemente por ser a cabeceira e, polo tanto, a diferenciación entre pueblo e parroquia é difusa) e o concello. No tocante a España, a identificación é lixeiramente superior á dos anteriores. Finalmente, cos que os entrevistados mostran unha maior afinidade é co pueblo e con Galicia. Para chegar a esta conclusión (reflectida no Gráfico 3) seguíronse modelos de estudo baseados na teoría da identidade coñecida como Fusión da Identidade ${ }^{31}$. Esta teoría pretende explicar os comportamentos extremos (sacrificios tanto positivos como negativos; por exemplo, mortes en pelexas deste tipo) que algúns membros dun grupo son capaces de realizar en defensa doutros membros do mesmo. Segundo esta teoría, os individuos fusionados perciben ao grupo e a eles mesmos como a mesma cousa. Neste aspecto, dos datos analizados despréndese que os compoñentes da mostra analizada tiñan unha maior predisposición no pasado para sacrificarse polo grupo da que teñen na actualidade. Así, por outra banda, no segundo cuestionario, ao ítem "de mozo estaba disposto a sacrificarme polo meu pueblo", 10 dos 11 entrevistados manifestaron que se sentían de acordo.

De todos os xeitos, estes resultados hai que tomalos con precaucións (en especial en relación a Galicia ou España), pois estas identificacións puideron mudar.

${ }^{31}$ Á. Gómez Jiménez, “Las raíces de la violencia...”, páxs. 13-36. 
Así, é común que sufran variacións en función de acontecementos externos, por exemplo, éxitos deportivos ou agresións. O que si se pode derivar é que existe unha tendencia que fai pensar que había un alto grao de interiorización con respecto á pertenza ao pueblo; pois, tomando o mesmo exemplo do parágrafo anterior ("de mozo estaba disposto a sacrificarme polo meu pueblo"), eses niveis de aceptación non son acadados, nin de cerca (como máximo 2), para as outras entidades.

Tamén é certo que ningunha das entidades é rexeitada por completo, polo tanto, poderíase pensar que no caso da parroquia existe unha vinculación de tipo relixiosa, mentres que co pueblo esta vinculación é maior, tal vez incluso se remonte á época dos castros (en base ao xa mencionado do emprazamento dos mesmos e da toponimia).

No tocante á continuación de algún tipo de animadversión entre estas aldeas, os entrevistados afirmaban que non, pero algo si que perviviu. A modo de exemplo, no refraneiro popular persiste un dito: "terminarán os ladróns en Moialde cando se termine a lerica [herba mala] en Arzoá [outra aldea na que hai gran cantidade desta herba]". Non obstante, a súa incidencia é case testemuñal, reducida a este tipo de exemplos.

\section{ConClusións}

En primeiro lugar, indicar que os resultados aquí obtidos circunscríbense a un caso concreto. Polo tanto, para poder xeneralizalos precisaríase, por exemplo, doutros estudos que os testasen cuantitativamente noutros lugares. Dito isto, as conclusións que a continuación se expoñen poderían servir como hipóteses orientativas deses traballos.

Feita a puntualización anterior, indicar que neste mundo rural existían dous tipos ben diferenciados de violencia intercomunitaria: o derivado da competencia polas mulleres, as mozas, e o que era resultado da loita por aqueles bens que tiñan un carácter colectivo, os comunais. Este tipo de conflitos eran algo habitual, que tiñan unha periodicidade cíclica propia do tempo rural agrícola, baseado nas estacións.

Un deles, o derivado do moceo, estaba xa ritualizado (interiorizado) e circunscrito ao cortexo. Por unha parte, para os homes era a ocasión de demostrar a súa valentía, a súa valía; ao mesmo tempo que resgardaban un ben comunitario indispensable para a continuidade da entidade poboacional, as mozas. Por outra banda, para as mulleres, era a oportunidade de seleccionar a aquel que puidese ser o máis apto como compañeiro reprodutivo. Esta violencia era terreo exclusivo dos homes e, en especial dos mozos (aproximadamente de 16 a 25 anos). Tiña unhas datas e lugares prefixados e coñecidos por todos os membros da comunidade. 
O outro tipo, a violencia derivada da competencia polos medios produtivos (polo uso dos comunais), non posuía unha ritualización como a referente ao caso anterior. Tiña unha xustificación na defensa dos medios de subsistencia básicos, por iso, as armas que se empregaban podían facer máis dano. Por outro lado, debido a cuestións xeográficas estaba circunscrita aos distintos pueblos colindantes, é dicir, o seu radio de incidencia era máis reducido. Igualmente que no caso anterior era un campo vetado ás mulleres e aos nenos.

Ambos os dous rexíanse polos usos e costumes propios da zona e procurábase, na medida do posible, manter afastados deles a axentes exóxenos á comunidade, como podían ser as autoridades. A elas, habitualmente, só se acudía en casos extremos, como mortes ou feridos graves.

Tanto un tipo como o outro tiñan unha función cohesionadora do grupo, en oposición a outros (outros grupos). Sendo o grupo, nesta zona concreta, o pueblo (a aldea), co cal se tiña unha identificación maior que coa parroquia ou co concello. O nivel de identificación facía que, no caso de agresión externa, os problemas internos (tamén habituais, pois dentro do propio pueblo existía unha tendencia individualizadora que provocaba competencia polos recursos, como por exemplo, cambio de marcos ou uso de regadíos) fosen esquecidos e todos os membros da comunidade fixesen fronte común contra o foráneo. Esta identificación, podía chegar nalgúns casos ata a fusión da identidade o que facilitaba o sacrificio polo grupo, a realización de condutas extremas como os homicidios.

Este mundo violento estaba directamente relacionado co sistema económico e social preexistente que, con pequenas modificacións, se remontaba longo tempo atrás. Este sistema ancestral foi modificado por unha nova organización produtiva e social, con orixe na emigración e na masificación do acceso á educación pública e obrigatoria e aos medios de comunicación de masas, como a televisión e a radio (elementos difusores de cultura dun potencial incomparable cos ata ese momento existentes no rural galego).

O punto de inflexión sitúase nos anos 60, coa extensión da emigración á Europa Central. Pois, antes outros procesos migratorios (América) ou a coerción exercida durante a Guerra Civil e a posguerra non conseguiran modificar o sistema e, polo tanto, esta violencia persistiu.

A emigración modificaba, directamente, aos que saían, e, indirectamente, aos que quedaban, influenciados polos primeiros (o traballo por campañas era habitual e, dende o centro de Europa, regresar nas vacacións era factible, non así dende América). Ademais, os xa citados medios de comunicación de masas, tamén xogaron un papel destacado na transmisión dunha cultura oficial (estatal) que modificaba a existente. 
Todo en conxunto fixo mudar o sistema social e económico. E como consecuencia, as causas desta violencia intercomunitaria deixaron de ter vixencia, e polo tanto, acabou practicamente por desaparecer.

Con respecto ás hipóteses de partida propostas, destacar que se cumpriron na súa maioría, coas excepcións da importancia da caza, e fundamentalmente, da identificación co pueblo en lugar de coa parroquia. Polo tanto, en conxunto, poden constituír unha boa hipótese de partida para, como se indicou ao comezo deste apartado, a realización doutras investigacións máis amplas e cuantitativas.

Finalmente, indicar que este campo de estudo ofrece moitas posibilidades de futuro, por aínda estar pouco investigado. Sería aconsellable a realización de novas investigacións que afonden nesta temática. Para iso, parece axeitado, por exemplo, a complementación de fontes cualitativas, como as empregadas aquí, con outras de natureza máis cuantitativa, como os datos que se poderían extraer da prensa da época, de procedementos xudiciais ou doutros arquivos administrativos.

\section{BIBLIOGRAFÍA}

Arias, Andrés e Fernández Ramírez, Baltasar, "La encuesta como técnica de investigación social”, en Antonio José Rojas, Juan Sebastián Fernández e Cristino Pérez (Eds.), Investigar mediante encuestas. Fundamentos teóricos y aspectos prácticos, Madrid, Síntesis, 1998, páxs. 31-49.

Cabo Villaverde, Miguel e Vázquez Varela, José Manuel, Las otras guerras de nuestros antepasados: la violencia intercomunitaria en la Galicia rural contemporánea, Documento Inédito, 2014.

Castro Pérez, Xavier, Servir era o pan do demo. Historia da vida cotiá en Galicia. Séculos $X I X$ e XX, Vigo, Nigraterra, 2007.

Conley, Carolyn, "The Agreeable Recreation of Fighting”, Journal of Social History, 33 (1) (1999), páxs. 57-72.

Gómez Jiménez, Ángel, "Las raíces de la violencia en la adolescencia. Cuando el individuo está fusionado con el grupo", en Hacia una protección integral del menor: XIX Seminario "duque de Ahumada", Madrid, Ministerio del Interior, 2008, páxs. 13-36.

González Gómez, Andrés e Padilla, José Luis, "La entrevista", en Antonio José Rojas, Juan Sebastián Fernández e Cristino Pérez (Eds.), Investigar mediante encuestas. Fundamentos teóricos y aspectos prácticos, Madrid, Síntesis, 1998, páxs. 141-153.

Hervés Sayar, Henrique e outros, "Resistencia y organización. La conflictividad rural en Galicia desde la crisis del Antiguo Régimen al franquismo", Noticiario de Historia Agraria, 13 (1997), páxs. 165-191.

Lison Tolosana, Carmelo, Antropología cultural de Galicia, Madrid, Akal, 1979.

Manzano Arrondo, Vicente G., Rojas Tejada, Antonio José e Fernández Prados, Juan Sebastián, Manual para encuestadores, Barcelona, Ariel, 1996.

Mariño Ferro, Xosé Ramón, Antropoloxía de Galicia, Vigo, Xerais, 2000. 
Ministerio de Educación Cultura y Deporte, Portal de Archivos Españoles (PARES), "Interrogatorio de la Feligresía de San Miguel de Progo y mas cotos e Interrogatorio de Santa María de Moyalde" [en línea], disponible en < http://pares.mcu.es $>$ [Consulta: 02/03/2015].

Padilla, José Luis, González Gómez, Andrés e Pérez Meléndez, Cristino, "Elaboración del cuestionario", en Antonio José Rojas, Juan Sebastián Fernández e Cristino Pérez (Eds.), Investigar mediante encuestas. Fundamentos teóricos y aspectos prácticos, Madrid, Síntesis, 1998, páxs. 115-140.

Pinker, Steven, Los ángeles que llevamos dentro. El declive de la violencia y sus implicaciones, Barcelona, Espasa, 2012.

Redondo-Cardeñoso, Jesús Ángel, "Violencia y sociedad rural. La Tierra de Campos palentina (1917-1923)", Historia Agraria, 51 (2010), páxs. 81-108.

Rodríguez Cruz, Xosé e Lourenço Fontes António, Mitos, crenzas e costumes da Raia Seca, Vigo, Ir Indo, 2004.

Saavedra Fernández, Pegerto, La vida cotidiana en la Galicia del Antiguo Régimen, Barcelona, Crítica, 1994.

Scott, Jim, "Formas cotidianas de rebelión campesina", Historia Social, 28 (1997), páxs. 13-39.

Tilly, Charles, Tilly, Luise A. e Tilly, Richard, El siglo rebelde, 1830-1930, Zaragoza, Prensas Universitarias de Zaragoza, 1997.

Tratado de limites entre Portugal e Hespanha assignado em Lisboa pelos respectivos plenipotenciarios aos 29 de setembro de 1864, [en línea], disponible en < http://google.es/ books?id=J7gMAAAAYAAJ\&hl=es $>$ [Consulta: 02/03/2015].

Vaquinhas, Irene Maria, Violência, justiça e sociedade rural. Os campos de Comimbra, Montamor-o-Velho e Penacova de 1858 a 1918, Porto, Afrontamento, 1996. 
